Occurrences at Los Alamos National Laboratory:

What Can They Tell Us?

Richard A. Reichelt*

A. Jeffery Eichorst*

Marc E. Clay*

Rita J. Henins*

Judith D. DeHaven*

Richard J. Brake* 


\section{DISCLAIMER}

This report was prepared as an account of work sponsored by an agency of the United States Government. Neither the United States Government nor any agency thereof, nor any of their employees, make any warranty, express or implied, or assumes any legal liability or responsibility for the accuracy, completeness, or usefulness of any information, apparatus, product, or process disclosed, or represents that its use would not infringe privately owned rights. Reference herein to any specific commercial product, process, or service by trade name, trademark, manufacturer, or otherwise does not necessarily constitute or imply its endorsement, recommendation, or favoring by the United States Government or any agency thereof. The views and opinions of authors expressed herein do not necessarily state or reflect those of the United States Government or any agency thereof. 


\section{DISCLAIMER}

Portions of this document may be illegible in electronic image products. Images are produced from the best available original document. 


\title{
Occurrences at Los Alamos National Laboratory: What Can They Tell Us?
}

\author{
by \\ Richard A. Reichelt, A. Jeffery Eichorst, Marc E. Clay, Rita J. Henins, \\ Judith D. DeHaven, and Richard J. Brake
}

\begin{abstract}
The authors analyzed the evolution of institutional and facility response to groups of abnormal incidents at Los Alamos National Laboratory (LANL). The analysis is divided into three stages: (1) the LANL response to severe accidents from 1994 to $1996,(2)$ the LANL response to facility-specific clusters of low-consequence incidents from 1997 to 1999 , and (3) the ongoing development of and response to a Laboratory-wide trending and analysis program. The first stage is characterized by five severe accidents at LANL-a shooting fatality, a forklift accident, two electrical shock incidents, and an explosion in a nuclear facility. Each accident caused LANL and the Department of Energy (DOE) to launch indepth investigations. A recurrent theme of the investigations was the failure of LANL and DOE to identify and act on precursor or low-consequence events that preceded the severe accidents. The second stage is characterized by LANL response to precursor or lowconsequence incidents over a two-year period. In this stage, the Chemistry and Metallurgy Research Facility, the Los Alamos Critical Experiments Facility, and the Los Alamos Neutron Science Center responded to an increase in low-consequence events by standing down their facilities. During the restart process, each facility collectively analyzed the lowconsequence events and developed systemic corrective actions. The third stage is characterized by the development of a Laboratory-wide trending and analysis program, which involves proactive division-level analysis of incidents and development of systemic actions. The authors conclude that, while the stages show an encouraging evolution, the facility standdowns and restarts are overly costly and that the institutional trending and analysis program is underutilized. The authors therefore recommend the implementation of an institutional, mentored program of trending and analysis that identifies clusters of related low-consequence events, analyzes those events, and develops systemic actions to avoid both severe accidents and standdowns.
\end{abstract}




\section{Introduction}

Los Alamos National Laboratory (LANL or the Laboratory) presents unique challenges to someone who wants to understand the causes of its accidents and abnormal incidents. The most obvious of these are the institution's size and complexity. LANL is situated on a 43square-mile area of northern New Mexico called the Pajarito Plateau. Fifty technical areas and over 2,000 buildings are spread over the region's canyons and mesas. Within those buildings, more than 13,000 employees and subcontractors work on diverse projects-nuclear weapons research, high-performance computing, the Human Genome Project. However, the very scope and diversity of projects at LANL can be its enemy: the richness is accompanied by a multitude of accident scenarios.

Each year Los Alamos has about 250 incidents that meet Department of Energy (DOE) reporting criteria. These incidents include hazardous waste spills, oven fires, radioactive contaminations, car wrecks, electrical safety issues, pressurized storage drums, and near misses to significant accidents. LANL's Occurrence Investigation Group (ESH-7) assists facility managers in investigating each of the incidents. The complex process of investigating a single occurrence, which involves soliciting input from workers, managers, and subjectmatter experts, completing causal analyses, and achieving consensus on causes and corrective actions, is itself a challenge to understanding occurrences at LANL.

Groups of occurrences present additional challenges. How does LANL as an institution, as well as its component divisions and facilities, analyze a cluster of incidents? At what thresholds do LANL facilities react to these incidents? When does LANL initiate new institutional policies, processes, or procedures in response to a series of related incidents? These questions are all aimed at the method that LANL uses to manage itself and plan for and respond effectively to operational trends.

The LANL response to occurrences can be divided into three stages. The first stage is characterized by the Laboratory response to a set of severe accidents between 1994 and 1996. These accidents resulted primarily from an institutional failure to respond to precursor or low-consequence incidents. The second stage, which began in 1997, is characterized by facility standdowns and restarts in response to clusters of low-consequence incidents. These facility restarts have included reviews of past occurrences for common causes and the development of systemic corrective actions. The third stage, which was first introduced in 1996 and continues to evolve, is characterized by the development of an institutional program for evaluating occurrences. The program requires quarterly line-management reviews of all occurrences to identify trends and develop corrective actions before accidents occur. This paper explores the three stages of LANL responses to incidents, describes the evolution from reactive to more proactive types of occurrence analysis, and points to areas where improvements can be made in the analysis and prevention of incidents. 


\section{Laboratory Response to Severe Accidents, 1994 to 1996}

\section{A. Overview}

This section describes a series of severe accidents that took place at LANL between 1994 and 1996. These accidents resulted in one fatality, three severe injuries, and one near miss to a fatality or a severe injury. In general, this section shows how LANL and DOE failed to identify and act on precursor or low-consequence incidents that could have prevented the accidents.

\section{B. Description of Incidents}

The Laboratory and DOE have historically responded to severe accidents in a reactive manner. When a severe accident occurred, LANL took immediate actions to minimize the possibility of a similar accident. The Laboratory suspended the type of operation being performed at the time of the accident, and either the Laboratory or DOE initiated an intensive, formal incident investigation. The investigation was focused primarily on identifying the causes of the incident. Corrective actions were quickly developed to allow the resumption of any Laboratory-wide operations that were suspended after the accident.

Figure A lists a series of severe accidents that took place at LANL over a two-year time frame.

\begin{tabular}{|c|c|c|}
\hline Type of Incident & Date & Description \\
\hline Fatal Gunshot & Dec 1994 & $\begin{array}{l}\text { During a simulated attack exercise, a security officer inadvertently } \\
\text { loaded a magazine of live ammunition into his duty weapon and fired a } \\
\text { burst at another security officer. The second officer died after being } \\
\text { struck in the head and arm. The participants had been using weapons } \\
\text { that fire blank ammunition and infrared beams. }\end{array}$ \\
\hline $\begin{array}{l}\text { Forklift Pins } \\
\text { Driver }\end{array}$ & Nov 1995 & $\begin{array}{l}\text { An employee accidentally drove the wheels of his forklift off a concrete } \\
\text { building apron. The forklift rolled over in a ditch and pinned the } \\
\text { employee's neck underneath the overhead guard. Personnel from nearby } \\
\text { buildings were able to lift the forklift off the driver's neck, and the } \\
\text { employee was rescued and recovered. }\end{array}$ \\
\hline $\begin{array}{l}\text { Mason Tender } \\
\text { Shocked }\end{array}$ & Jan 1996 & $\begin{array}{l}\text { A mason tender who was operating a jackhammer received a severe } \\
\text { electrical shock when he struck a buried } 13,200 \text {-volt electrical line. The } \\
\text { mason tender was burned and rendered unconscious. He remains in a } \\
\text { coma and requires } 24 \text {-hour hospital care. }\end{array}$ \\
\hline $\begin{array}{l}\text { Student Employee } \\
\text { Shocked }\end{array}$ & Jul 1996 & $\begin{array}{l}\text { A graduate student received an electrical shock and was rendered } \\
\text { unconscious while he was conducting voltage tests on a microwave oven. } \\
\text { After removing the protective cover for the oven, he received a } 4000 \text {-volt } \\
\text { shock when he incorrectly attached a test probe to energized parts. }\end{array}$ \\
\hline $\begin{array}{l}\text { Explosion and } \\
\text { Fire }\end{array}$ & Nov 1996 & $\begin{array}{l}\text { As part of an experimental outgassing procedure, a chemist placed a } \\
\text { stainless steel canister of misidentified materials inside an oven. After } \\
\text { normal working hours, when the procedure was unattended, the canister } \\
\text { exploded and destroyed the oven and associated research equipment. }\end{array}$ \\
\hline
\end{tabular}

Figure A. Severe Accidents at LANL between 1994 and 1996 
The investigations of these severe accidents identified significant precursor or lowconsequence incidents. Before the fatal gunshot in December 1994, LANL experienced two such precursor incidents that involved poor controls of security exercises and ammunition. The first incident took place in August 1994 and involved an ES\&H specialist who observed the armory issuing blanks and weapons to personnel who still had functional weapons and live ammunition. The second incident took place in October 1994 and involved an exercise in which leaders asked briefing participants to remove live ammunition before receiving blank ammunition from the armory. An ES\&H specialist later found that one participant still had a speed loader containing live ammunition.

This pattern - $\mathrm{a}$ failure to act on low-consequence incidents preceding a serious accident-was repeated at LANL. Before the forklift accident in November 1995, operators had raised safety concerns about the lack of seat belts on forklifts. The Laboratory, however, failed to act on these concerns. The DOE analysis of the forklift accident stated

A personnel restraint system may have kept the operator inside the overhead guard and helped minimize the extent of his injury.

The severe shock of the mason tender in 1996 initiated a broad process of LANL selfexamination. The DOE and Laboratory initiated wide-ranging investigations into institutional work control policies, conduct-of-operations issues, and other systemic institutional issues. As with the previous severe accidents, investigators described a similar institutional inattention to precursor incidents.

Before the shock accident, LANL had experienced five precursor or low-consequence incidents in which personnel had cut through or drilled into live electrical lines. The associated reports identified inadequacies in electrical safety program development and training of personnel. However, LANL and the subcontractor did not act to fully correct the deficiencies in electrical safety procedures and training to prevent a recurrence. The Laboratory's failure to fully correct the deficiencies identified in the precursor incidents resulted in the severe shock of the mason tender. The DOE analysis of the accident stated

The management systems instituted at LANL have not been effective in correcting longstanding, well-defined programmatic weaknesses identified through internal and external assessments, past occurrences, and previous accident investigations, or in translating lessons learned in safe day-to-day operations at the Laboratory...

[The Subcontractor] did not implement the corrective action lessons learned from other similar reported incidents that required the use of electrical personal protective equipment for cutting and/or jackhammering concrete or soil. Because these procedures were not written, [the subcontractor] did not provide personal protective equipment training to each employee... 
With the microwave shock in July 1996 and the explosion in November 1996, the DOE and LANL initiated broad investigations into the safety practices of research and development (R\&D) employees at LANL. Both accidents involved work performed by graduate students and had numerous lower-consequence precursor incidents involving poor supervision of student work, near misses to significant injuries, and other similar incidents.

\section{Analysis of Response to Severe Accidents}

The severe accidents that took place at LANL between 1994 and 1996 share a failure to respond to low-consequence incidents. Each of the severe accidents had a set of precursors that, if properly analyzed and corrected, might have prevented the accident from happening. However, the institutional, division, or facility mechanisms were not in place at LANL to ensure that this type of analysis was performed consistently and in a sustained manner.

\section{Facility Response to Low-Consequence Incidents, 1997 to Present}

\section{A. Overview}

This section describes incidents at three facilities at LANL, the Chemistry and Metallurgy Research (CMR) facility, the Pajarito Canyon Site (TA-18), and the Los Alamos Neutron Science Center (LANSCE). Each of these facilities experienced a series of low-consequence incidents that led their division directors to stand down facility operations. This section details the occurrences leading up to the operational standdowns and the patterns of facility response.

In general, this discussion shows an improvement from the previously described response to severe accidents. Instead of using a severe accident as a catalyst for occurrence analysis, CMR, TA-18, and LANSCE have instead responded to series of low-consequence incidents. In addition, these LANL facilities show an evolution toward more systematic reviews of past occurrences, development of common cause analyses, and identification of systemic corrective actions. By initiating and then building on each other's restart processes, they have developed a significant model for analyzing occurrences.

\section{B. Chemistry and Metallurgy Research Facility}

The CMR facility was built at Los Alamos in 1952 to house research activities in analytical chemistry, plutonium and uranium chemistry and metallurgy, and other associated activities. Research at CMR supports major experimental programs at Los Alamos and within the DOE complex. These programs include nuclear materials process technology, waste minimization, environmental restoration, and support for the Waste Isolation Pilot Project (WIPP).

On September 2, 1997, the division director suspended operations at CMR. The facility was stood down in response to a series of incidents that appeared to have different causes-procedural violations, unsafe work practices, inadequate maintenance, poor conduct of operations, faulty hazard analysis, and performance of work outside the facility's authorization basis (i.e., licensing agreements). Figure B lists the occurrences in chronological order. 


\begin{tabular}{|c|c|c|}
\hline Type of Incident & Date & Description \\
\hline Pressure Inversion & Jul 1997 & $\begin{array}{l}\text { The closure of ventilation system exhaust dampers with the supply fans } \\
\text { running resulted in a pressure inversion at CMR. Maintenance personnel } \\
\text { had performed unauthorized work on an air dryer associated with the } \\
\text { compressor that supplies air to the operation mechanisms for the } \\
\text { dampers. }\end{array}$ \\
\hline Loss of Ventilation & Jul 1997 & $\begin{array}{l}\text { A leak in the basement of another facility caused the outage of an } \\
\text { electrical feeder line. The outage resulted in a complete loss of } \\
\text { ventilation at CMR for more than six hours. Radioactive contamination } \\
\text { migrated from open-front containment boxes and resulted in numerous } \\
\text { continuous air monitor (CAM) alarms. }\end{array}$ \\
\hline $\begin{array}{l}\text { Contamination } \\
\text { Incidents }\end{array}$ & Jul 1997 & $\begin{array}{l}\text { Several incidents occurred in which personnel or areas became } \\
\text { contaminated with plutonium isotopes and the contamination source } \\
\text { could not be positively identified. }\end{array}$ \\
\hline $\begin{array}{l}\text { Poor Response to } \\
\text { Incidents }\end{array}$ & Aug 1997 & $\begin{array}{l}\text { Several incidents occurred in which personnel did not adhere to good } \\
\text { radiological practices (i.e., using a glovebox glove known to be } \\
\text { damaged) or properly respond to associated contamination incidents. }\end{array}$ \\
\hline $\begin{array}{l}\text { Zero Air to } \\
\text { Slotbox }\end{array}$ & Aug 1997 & $\begin{array}{l}\text { An investigation of a CAM alarm reveled that a slotbox had zero } \\
\text { airflow while employees had handled samples of americium- } 241 \text {. } \\
\text { Facility personnel discovered a discarded rubber glove had clogged the } \\
\text { exhaust ventilation grating for the box. }\end{array}$ \\
\hline $\begin{array}{l}\text { Near Miss to } \\
\text { Radiation } \\
\text { Exposure }\end{array}$ & Aug 1997 & $\begin{array}{l}\text { Two employees were nearly exposed to radiation during checks of oil- } \\
\text { filled viewing windows in hot cells. One of the cells contained a can } \\
\text { with radioactive materials. The employees did not visually check the hot } \\
\text { cell contents before lowering the radiation shield. }\end{array}$ \\
\hline Oven Fire & Aug 1997 & $\begin{array}{l}\text { A small fire occurred within a utility oven in a radiologically controlled } \\
\text { area. The oven was being used to dry a mop head that had been used to } \\
\text { clean floors in a radiological control area. The oven contained exposed } \\
\text { electric heating coils and vented into the room. Surveys of the mop head } \\
\text { revealed small amounts of radioactive material. }\end{array}$ \\
\hline $\begin{array}{l}\text { Facility } \\
\text { Standdown }\end{array}$ & Sept 1997 & The division director stood down the CMR facility. \\
\hline Failure of Backup & $\begin{array}{l}\text { Post- } \\
\text { Standdown }\end{array}$ & $\begin{array}{l}\text { Shortly after the standdown, the battery backup systems for all fire } \\
\text { alarm panels were discovered to have failed. }\end{array}$ \\
\hline
\end{tabular}

Figure B. Occurrences Preceding the CMR Standdown 
In describing his reasons for standing down operations, the division director provided the following explanation:

In high-risk and complex operations at nuclear facilities, procedural formalities are required to ensure safety. By themselves, plain "common sense" or basic safety precautions and good practices are just not enough for total safe operation. Without written procedures, adequate training, and adequate supervision, the stage is set for incidents. If people are lucky, as was the case in nearly all of the CMR incidents, the impacts of not having formal guidance, or of not following procedures, or of not having adequate training and supervision will not be severe. But what if they are not lucky? It is time for CMR management and employees to stop relying on luck to keep them out of serious trouble. As the recent incidents have demonstrated, management's failure to be actively involved in day-to-day operations, and employees' failure to follow procedures, not only can impact individual safety, but also the safety of unwitting coworkers, and perhaps even the facility's ability to remain in operation.

As expected, an investigation revealed diverse direct causes that triggered each of the incidents. At the same time, however, it revealed several broad underlying causal factors and facility issues. Although not nominally a "common cause analysis," this process was later taken up and refined by other facilities in their restart activities. Common causal factors for the incidents at CMR are listed below.

\section{Aging Facility}

A primary cause of occurrences leading to the standdown is the age and condition of CMR. The facility was designed and constructed according to 1949 Universal Building Codes and is nearing the end of its design lifetime. It does not meet current standards for a nuclear research facility. At least three engineering reviews of CMR have been conducted in the past 30 years. The conclusion of each review was that infrastructure equipment had reached, or was reaching, end-of-life failure. The reviews also recommended that infrastructure equipment be upgraded or that a new building be constructed. These recommendations were never adequately implemented.

As a result, a large number of occurrences at CMR reflect an aging facility infrastructure. An example was the August 1997 occurrence involving the discovery of zero airflow to an openfront glovebox. In the occurrence report, the facility manager stated

The CMR facility is an aging nuclear facility with engineered safety systems that do not meet current standards, such as flow indicators on open-front boxes and hoods.

In the post-standdown report detailing the discovery of failed battery backup systems in October 1997 , the facility manager stated

Seven of the panels were Autocall, type NA-3 panels, that were manufactured in the 1970 s and had been in service in CMR for well over twenty years. The NA-3 panels were no longer manufactured and new spare parts were not available. 
In addition to these problems of aging infrastructure, the CMR facility has problems with legacy equipment and contamination hazards (both radiological and chemical) left over from previous operations. Poor historical practices were not systematically identified or corrected. Consequently, many occurrences at CMR reflect these legacy issues. An example is the plutonium contamination incidents in July and August 1997 that resulted from the historical and inadequately controlled use of plutonium- 238 .

\section{Poorly Defined Facility Authorization Basis}

A second cause of occurrences leading to the CMR standdown was a poorly defined facility authorization basis. Before the standdown, the facility authorization basis did not fully describe safety-related equipment and did not include a hazard analysis that covered all activities and conditions within the facility. Consequently, the causes for many occurrences at CMR were eventually traced to this poorly defined and poorly understood authorization basis.

An example of this problem was the July 1997 occurrence involving unauthorized operations. As part of a review of the facility's authorization basis, DOE reviewed operations at CMR and identified 13 unauthorized activities. These included improper facility modifications, improper storage of drums containing uranium-233, inadequate analysis of hazards in electrical upgrades, improper storage of gas cylinders, and other incompletely analyzed activities. Again, all these activities had hazards that were never properly identified or addressed by the facility authorization basis.

\section{Management System Problems}

Many of the occurrences before the standdown also showed a failure to define formal policies and procedures. One example of this deficiency was the oven fire in August 1997. Facility management was not aware that personnel were using the ovens to dry mop heads and then analyzing the leftover residues. The personnel who used this process had never analyzed it for hazards. Radiation protection and fire protection experts did not review the process to see if the oven, its configuration, and its controls were adequate for the process being described.

In the occurrence report of the oven fire, the facility manager stated

This incident occurred because the hazards of the activity were not adequately defined and analyzed to ensure that appropriate controls were in place before the activity was performed. The personnel operating the oven had a good understanding of the radiological hazards; however, they were not aware of the hazards associated with the oven and therefore did not provide appropriate controls that could have prevented this incident.

Inadequate administrative controls and other management system problems were an underlying cause of many other occurrences leading up to the standdown. 


\section{Safety Culture Problems}

A review of occurrences following the standdown also identified several persistent problems related to the safety culture at the facility. These included (1) the management belief that R\&D at CMR was difficult to predict or analyze and was therefore not subject to procedural constraints; (2) a perception by workers that they must "produce"; (3) a lack of involvement by management in day-to-day activities; and (4) the targeting of worker errors in past occurrences. Management acknowledged that these chronic problems produced a strained and difficult safety culture that did not learn from its mistakes.

\section{CMR Facility Response}

After the standdown, CMR management, LANL, and DOE implemented or recommitted to several broad corrective actions. These actions included completion of the following actions:

- Implement a new management structure for CMR.

- Formally review all activities to ensure they are performed safely and in accordance with the safety authorization basis.

- Implement a new facility authorization basis that includes new technical safety requirements.

- Implement improved work control policies and procedures and formal conduct of operations.

- Commit to an effective management involvement program and improve the facility's behavior-based safety program.

- Replace the facility's outdated fire alarm panels and restart efforts to upgrade the facility infrastructure.

The CMR restart process exposed many broad problems of infrastructure, management, worker attitude, safety culture, and administrative controls at the facility. The facility was restarted in April 1998. Subsequently, other facilities facing similar problems adopted and improved on CMR's response to its standdown.

\section{Pajarito Canyon Site}

Pajarito Canyon Site (TA-18) has been used to conduct criticality experiments at Los Alamos since the 1940s. The facility contains three separate laboratories, or "kivas," which are operated remotely from individual control rooms in a central building. The kivas house a variety of experimental critical assemblies, including the Solution High-Energy Burst Assembly (SHEBA) and Planet assemblies. It is worth noting that the remotely operated kivas were constructed in the mid-1940s because of criticality accidents that resulted in two employee deaths.

On August 12, 1998, the responsible division director suspended operations at TA-18. The reason for the standdown was a series of incidents involving the overall failure to operate the facility within DOE requirements. Figure $C$ lists the occurrences in chronological order. 


\begin{tabular}{|c|c|c|}
\hline Type of Incident & Date & Description \\
\hline $\begin{array}{l}\text { Personnel Error } \\
\text { Results in Scram }\end{array}$ & May 1997 & $\begin{array}{l}\text { A researcher failed to ensure the purge gas accumulator pressure was in } \\
\text { the required range. The SHEBA critical assembly scrammed as a result. }\end{array}$ \\
\hline $\begin{array}{l}\text { Loss of Control of } \\
\text { Positive Reactivity } \\
\text { Insertion }\end{array}$ & Feb 1998 & $\begin{array}{l}\text { An operator lost joystick control of positive reactivity insertion into the } \\
\text { Planet assembly. Once the operator lost control, he initiated a scram, and } \\
\text { the assembly shut down. Troubleshooting revealed software problems } \\
\text { with the watchdog control circuitry for the insertion. }\end{array}$ \\
\hline $\begin{array}{l}\text { Calibration not } \\
\text { Documented }\end{array}$ & May 1998 & $\begin{array}{l}\text { The facility manager learned that the facility's authorization basis was } \\
\text { violated when the startup channel instrument calibrations for the } \\
\text { SHEBA assembly were not documented in } 1996 \text {. }\end{array}$ \\
\hline $\begin{array}{l}\text { Modification } \\
\text { made without } \\
\text { Screening }\end{array}$ & May 1998 & $\begin{array}{l}\text { Maintenance personnel installed a lightning protection system for the } \\
\text { SHEBA building and Kiva } 1 \text { warehouse that tied into the existing } \\
\text { grounding system. The modification was made without determining } \\
\text { whether it fits the facility's authorization basis and could have affected } \\
\text { the electrical systems for the scram chain. }\end{array}$ \\
\hline $\begin{array}{l}\text { Procedures } \\
\text { Violated }\end{array}$ & June 1998 & $\begin{array}{l}\text { Researches violated required procedures to notify the guard station, post } \\
\text { an exclusion area, and activate warning lights before conducting } \\
\text { radiography experiments. }\end{array}$ \\
\hline $\begin{array}{l}\text { Inadequate Area } \\
\text { Sweep }\end{array}$ & Jul 1998 & $\begin{array}{l}\text { While preparing for a critical experiment with the Planet assembly, } \\
\text { researches discovered they had missed a security guard during a sweep } \\
\text { of the radiological control area. }\end{array}$ \\
\hline $\begin{array}{l}\text { Criticality Safety } \\
\text { Limit Violated }\end{array}$ & Aug 1998 & $\begin{array}{l}\text { During a demonstration of nuclear instrument response for criticality } \\
\text { safety training, researchers placed onto a cart a mass of special nuclear } \\
\text { material that exceeded the applicable administrative mass limit for a } \\
\text { single storage area. The mass violation was corrected within a few } \\
\text { seconds. }\end{array}$ \\
\hline $\begin{array}{l}\text { Facility } \\
\text { Standdown }\end{array}$ & Aug 1998 & The division director stood down TA-18. \\
\hline
\end{tabular}

Figure C. Occurrences Preceding the TA-18 Standdown

The restart process at TA-18 began in a similar fashion to the earlier one at CMR. Facility personnel performed a process and activity analysis through an evaluation of the personnel, procedures, training, and infrastructure that supported each activity. At the same time, the facility also explicitly identified common causes among past occurrences.

The investigative strategy was to examine past occurrences, identify underlying similarities between the causal analyses, and develop systemic corrective actions. Although the full causal analysis was not complete before the restart process began, TA-18 management used a preliminary draft analysis to guide restart activities. The following is a summary of common cause factors. 


\section{Inadequate Facility Configuration and Hazard Controls}

An investigation of the incidents pointed out that TA-18 relies on an inadequate system of facility configuration and hazard controls. One example of this deficiency is the engineering controls used to govern the proximity of fissile materials. In general, the facility uses remote operations and design features that physically separate the individual components of a critical mass to provide safety. Specialized software programs govern the proximity of these components.

These software controls are ineffective and have been recognized as a general problem at other LANL facilities for many years. Two occurrences at TA-18 involved this problem of the software governing mechanisms. Both the February 1998 loss of control of the reactivity insertion into the Planet assembly and the September 1998 post-standdown failure of a hydraulic ram to respond appropriately to commands were traced to inadequate qualityassurance testing of the software.

The investigation also identified inadequate administrative controls. Although formal procedures had been implemented at TA-18, management did not ensure these controls effectively mitigated the hazards not addressed by engineering controls. For example, the failure to conduct proper sweeps for personnel in the area or provide proper notifications before initiating experiments in June and July 1998 was the direct result of poor administrative controls and processes. No procedures at TA-18 existed to conduct the sweeps, and the facility relied on informal training to disseminate this information. In describing these deficiencies, the facility manager stated

During the critique and follow-on meetings, it was apparent that personnel had differing opinions on sweep procedures and requirements. Although on-the-job training (OJT) had been provided to personnel, no detailed requirements were documented in procedures for personnel to follow. This is a significant conduct of operations concern because it resulted in personnel performing the task in a variety of ways with unacceptable results.

Another example of poor administrative controls was the use of informal memos in place of procedures. These memos were not sent through the review processes required of procedures. This lack of formality in procedural implementation and review was also a contributing factor in the series of TA-18 occurrences.

\section{Inadequate Supervision, Management, and Oversight}

The second common cause factor, which is related to the first, was a supervision and management issue. For many of the occurrences leading up to the standdown, TA-18 management did not ensure that operators were sufficiently trained, that procedures were in place or sufficiently reviewed, or that workers' activities were properly supervised. This informal management style did not lend itself to safe work practices and contributed to the incidents. Furthermore, the persistence of this informal management style for many years indicated a resistance on the part of management to increased formality of operations. 
In 1991, DOE completed a comprehensive Tiger Team safety review of all LANL operations. The team noted the following:

\begin{abstract}
[TA-18] is operated by a group of scientists who essentially do all of the "hands on" work associated with critical experiments. Historically, this community has operated somewhat at arms length from the remainder of the U.S. reactor community and has enjoyed a certain freedom of action that is largely unhindered by the formality and discipline which is so much a part of other reactors....
\end{abstract}

\begin{abstract}
LANL management style has delegated much authority and autonomy to lower levels of the organization. This management style certainly provides the research staff with the maximum latitude of activity so as not to stymie the creativity and ingenuity of those performing research. However, this same latitude is also extended to the production and operating levels of LANL. This management system has led to an informality of operations which is not consistent with the Secretary of Energy's new safety culture. A long history of successful operation of LANL has also led to complacency in compliance with the evolving safety and health orders, requirements, and standards and, furthermore, did not encourage striving for safety excellence....
\end{abstract}

The repeat occurrences suggest TA-18 has not fully resolved the paradox of these observations (i.e., management styles and information flows appropriate for research may not be appropriate for safety). The Tiger Team observations, in combination with the recent occurrences, also indicate persistent cultural issues that LANL and DOE have long recognized but have not addressed effectively.

\title{
Inadequate Resource Allocation
}

The third common cause factor among occurrences was a resource allocation issue. All of the TA-18 occurrences, as well as others in this paper, reflect operations in a time of reduced DOE budgets and strained resources. For example, the TA-18 standdown report noted that the facility manager operates without adequate staffing and consequently performs duties beyond simply "planning, oversight, and task performance issues." Also, the Laboratory failed to provide the Reactor Safety Committee, an oversight committee, with sufficient resources and authority in fulfilling its charter of evaluating and recommending improvements for TA-18. Funding for needed programmatic upgrades has also not been available. For example, when log amplifiers associated with reactor power neutron detectors did not perform as expected at the facility, an investigation identified a lack of DOE and Laboratory funds to replace cable runs installed in 1946. 


\section{TA-18 Facility Response}

Following the standdown in August 1998, TA-18 management developed processes, similar to those performed at the CMR facility, to resume operations and long-term strategies to correct systemic facility issues. To resume operations, line management developed and submitted Authorization Packages (APs) for all assigned activities at the facility. Line managers had to complete the following steps in the resumption process:

- Develop a resumption checklist for each activity that defines scope of work, documents hazards and controls, and documents whether the activity is adequately described in the facility's authorization basis and develop a resumption plan.

- Ensure equipment and personnel readiness through performance-based demonstrations of tasks before submitting the AP.

- Ensure closure of all prestart issues before submitting the AP for resumption approval.

Once these steps were completed, line managers submitted their APs for review by an independent team. This team consisted of subject-matter experts, safety committee participants, and other facility personnel not part of the activity. The team verified the following:

- Completion of the resumption checklist for each activity.

- Readiness of equipment and personnel for resumption through observations of tasks and personnel interviews.

- Completion of corrective actions for all prestart issues.

The TA-18 restart process has yet to be fully completed. The facility has implemented a phased restart of selected operations and is developing long-term strategic actions. The TA-18 restart improved on the earlier CMR process by formally implementing a common cause analysis and using that systemic analysis to restart the facility.

\section{Los Alamos Neutron Science Center}

LANSCE is a half-mile-long accelerator built atop a narrow mesa near the town of Los Alamos. Since it was completed in 1968 , the facility has been a center of research into nuclear interactions. More recently, the facility has been upgraded to produce intense neutron pulses for applications in materials science.

On February 5, 1999, the division director suspended operations at LANSCE because of a series of occurrences that had taken place since the start of the calendar year. Figure D shows the occurrences preceding the standdown in chronological order. 


\begin{tabular}{|l|l|l|}
\hline \multicolumn{1}{|c|}{ Type of Incident } & \multicolumn{1}{|c|}{ Date } & \multicolumn{1}{c|}{ Description } \\
\hline $\begin{array}{l}\text { Beryllium } \\
\text { Detected During } \\
\text { Cleanup }\end{array}$ & Jan1999 & $\begin{array}{l}\text { While cleanup operations were performed following a proton } \\
\text { radiography test, Industrial Hygiene personnel took routine swipes of the } \\
\text { containment vessel and unexpectedly discovered beryllium. The source } \\
\text { of the beryllium was traced to ceramic chips that were part of the target. }\end{array}$ \\
\hline $\begin{array}{l}\text { Permit Levels for } \\
\text { Chlorine } \\
\text { Exceeded }\end{array}$ & Jan 1999 & $\begin{array}{l}\text { In preparation for maintenance activities on the tower fan motor, the } \\
\text { building manager for a cooling tower opened the basin drain lines and } \\
\text { released approximately 200 gallons of highly chlorinated water. The } \\
\text { waster was discharged to the outfall without being dechlorinated. As a } \\
\text { result, National Pollutant Discharge Elimination System (NPDES) } \\
\text { permit limits for free chlorine levels were exceeded. }\end{array}$ \\
\hline $\begin{array}{l}\text { Target Cell Water } \\
\text { Found on Floor }\end{array}$ & Jan 1999 & $\begin{array}{l}\text { Technicians discovered a puddle of water on the floor of an experimental } \\
\text { room. While searching for the source of water, which appeared to be } \\
\text { coming from the target's bulk shield, one of the technicians inadvertently } \\
\text { stepped in the water. Beta contamination was subsequently discovered on } \\
\text { the technician's shoe. }\end{array}$ \\
\hline $\begin{array}{l}\text { Maintenance } \\
\text { Results in } \\
\text { Contamination }\end{array}$ & Feb 1999 & $\begin{array}{l}\text { A technician who had completed maintenance to three flow switches in } \\
\text { the target cell was detected with beta-gamma contamination on his face. } \\
\text { The three flow switches correspond to the water systems that supply } \\
\text { cooling water to the targets, reflectors, and moderators. }\end{array}$ \\
\hline $\begin{array}{l}\text { Repairs Result in } \\
\text { Contamination }\end{array}$ & Feb 1999 & $\begin{array}{l}\text { A technician who had finished maintenance on the flight path detected } \\
\text { beta-gamma contamination on his hands and pants. The radioactive was } \\
\text { tungsten-181. Investigators believe that the source of the activated } \\
\text { materials was a leak of target-cell cooling water. }\end{array}$ \\
\hline
\end{tabular}

Figure D. Occurrences Preceding the LANSCE Standdown

The ongoing process of restarting LANSCE operations has built on the earlier experiences at CMR and TA-18. To implement the resumption process, the division director has formed a number of committees to evaluate all aspects of the facility's safety performance and appointed one committee to act as a governing body for restart. One of the committees must identify systemic root causes for the past five years of occurrences at LANSCE and develop systemic corrective actions. This collective occurrence analysis has yet to be completed. Another committee must develop an effective means of disseminating lessons learned about facility safety issues.

In sum, the LANSCE strategy for restart is similar to the type of approach used by CMR and TA-18. The common cause analysis is being done for a wider range of occurrences than was done at either CMR or TA-18. The formal incorporation of the analysis into the facility resumption process also marks an improvement on previous facility restart efforts. 


\section{E. Analysis of Facility Response}

Over more than 50 years of operation, LANL has experienced facility standdowns but never three standdowns within such a short time frame or two standdowns simultaneously. LANL facilities are now struggling to solve problems of aging facility infrastructures, resource issues, management and supervision problems, workforce safety cultures, and other persistent problems. DOE audits, Laboratory self-assessments, and occurrence reports have identified these issues on numerous occasions. In fact, the facility analyses of occurrences are remarkably similar to each other in the types of systemic faults that they identify.

The recent successive standdowns and restarts at CMR, TA-18, and LANSCE strike a hopeful note. Each of these evolutions shows a progression and a fine-tuning of collective incident causal analysis. With each evolution, the involved facility has (1) performed a more structured analysis of past occurrences and (2) more fully incorporated the results of that analysis into the restart processes and corrective action development. As a result, the common cause analysis, by the time of the LANSCE standdown, has been formally incorporated into the restart mechanism.

This encouraging development at LANL is unfortunately connected to the costly processes of facility standdowns. Instead of using a systematic, proactive method of analyzing occurrences and corrective action development, these facilities have been impelled by operational standdowns to perform collective occurrence analysis. Still, the use of systemic causal analysis and its incorporation into restart processes is a positive development for LANL facilities.

\section{Development of an Institutional Trending and Analysis Program, 1996 to Present}

\section{A. Overview}

The previous sections have illustrated LANL's reactive methods of managing and responding to occurrences. The following section will show the Laboratory's attempt to put into place an institutional, proactive means of trending and analyzing occurrences to improve operations.

\section{B. Trending and Analysis Program}

In 1996, Los Alamos developed a program to trend and to analyze occurrences at the division level. At the Laboratory, there are 25 primary divisions, each with a different research focus or mission. Senior line managers, including division directors, were the intended recipients of the trending and analysis information. The program became part of a performance measure specified in the DOE's contract with LANL. The sequence of the trending and analysis portion was as follows: 
- The Occurrence Investigation Group submitted data quarterly (3-year bar charts, control charts, and occurrence summaries) for line management review.

- Senior line management analyzed the information, identified trends, developed corrective actions, and recorded the information in a quarterly self-assessment submitted to the Laboratory Director.

Planners had two reasons for developing this type of structure. First, they wanted to give responsibility for trending and analyzing occurrences to those overseeing day-to-day operations. Line managers, it was understood, had the in-depth technical and operational knowledge to best determine why incidents occurred. Furthermore, only line managers had the combined expertise and authority to develop and implement corrective actions for any systemic problems identified in their operations.

Second, the Occurrence Investigation Group's resources were too small to keep abreast of all Laboratory operational details and provide a comprehensive division-by-division analysis. For these reasons, the responsibility was placed on LANL line management to provide the trending and analysis for their respective divisions. ESH-7 was to become an information broker, providing packages of data tailored for the individual line manager/analyst.

This review structure eventually proved a smooth fit for the DOE's Integrated Safety Management (ISM) program, which LANL began introducing to the workforce in 1997. The main thrust of the program was to place responsibility for workplace safety on every member of the "line management chain"-workers, group leaders, division directors, the Laboratory Director-and not just on safety professionals. Other issues about the trending and analysis program, however, did not prove as good a match with ISM and are discussed later in this report. Figure $\mathrm{E}$ shows a flowchart of the original review process.

\section{Data Section}

Difficult questions had to be answered in developing the data packages: What was the best way to give line managers a clear snapshot of quarterly division performance? What information would be useful to all LANL senior line managers, regardless of the size or mission of their divisions? 


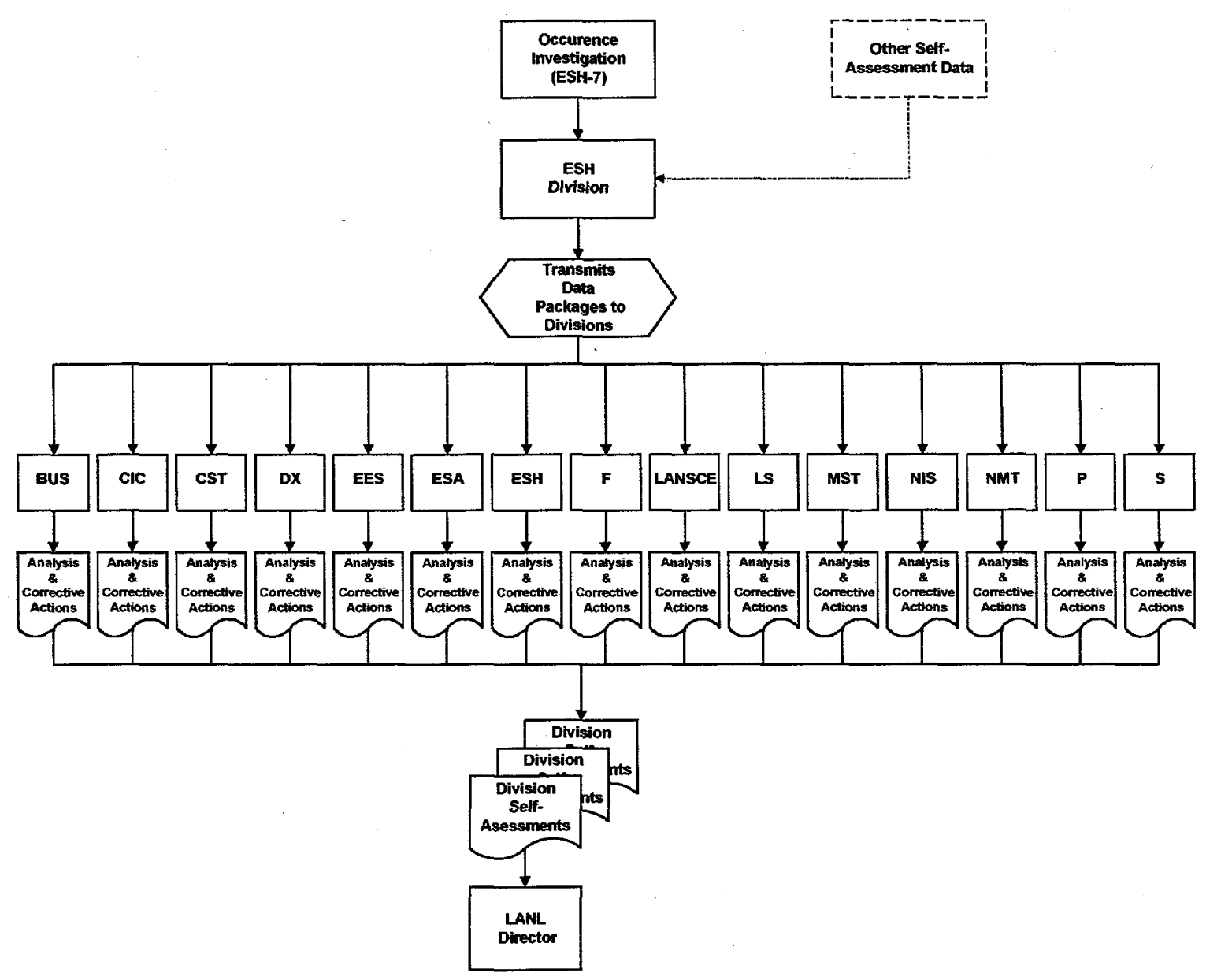

Figure E. Flowchart of Review Process for Occurrence Data

The key here was to find a technique that worked for a large, diverse facility such as the Laboratory. Participants in planning sessions, including LANL line management, support organizations, DOE representatives, and ESH-7, eventually settled on a dual structure: (1) quantitative data, consisting primarily of bar charts and graphs showing a division's performance over a three-year period, and (2) qualitative information, consisting of brief summaries of each occurrence, causal factors, and actions taken.

The quantitative data was primarily in the form of bar charts and represented numbers, types, and causal factors of occurrences. Line management did not want to use control charts or other statistical process techniques for analyzing the occurrence data. Such an option, they believed, could result in underreporting of occurrences. If the focus was purely on "numbers," then facilities might not report all their occurrences. For similar reasons, developers also did not want to set numerical targets for the occurrence performance indicator. What was considered more important was the structure of the review processhaving each division's managers and subject-matter experts systematically review groups of occurrence data on a quarterly basis and use it as a reference point for identifying trends or actions in the data. 
Distribution of Occurrences by Division at LANL

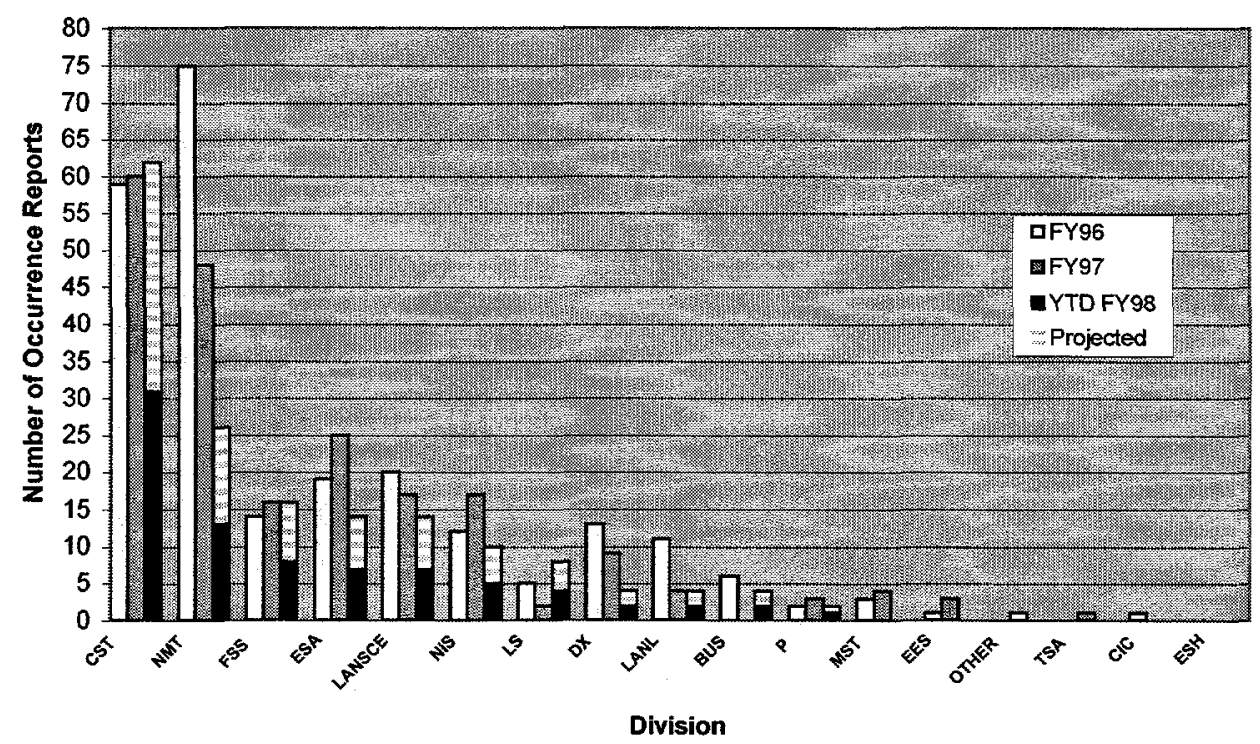

Figure F. Sample Bar Chart in Data Package

Figure F shows a typical bar chart for the data package. This chart shows the number of occurrences that took place for each division at LANL during a particular time frame over a three-year period. Other, similar charts provided information about types and causal factors of occurrences. Although planners had excluded control charts from the primary data packages, ESH-7 provided these charts to selected divisions as supplemental information. With the assistance of LANL's Quality Assurance Group (ESH-14), ESH-7 developed C-type control charts that detailed numbers and types of occurrences for each division over three-year time frames. C-type charts were chosen because the number of incidents is small in comparison to the actual number of successful operations. Figure $\mathrm{G}$ shows a typical control chart for a data package.

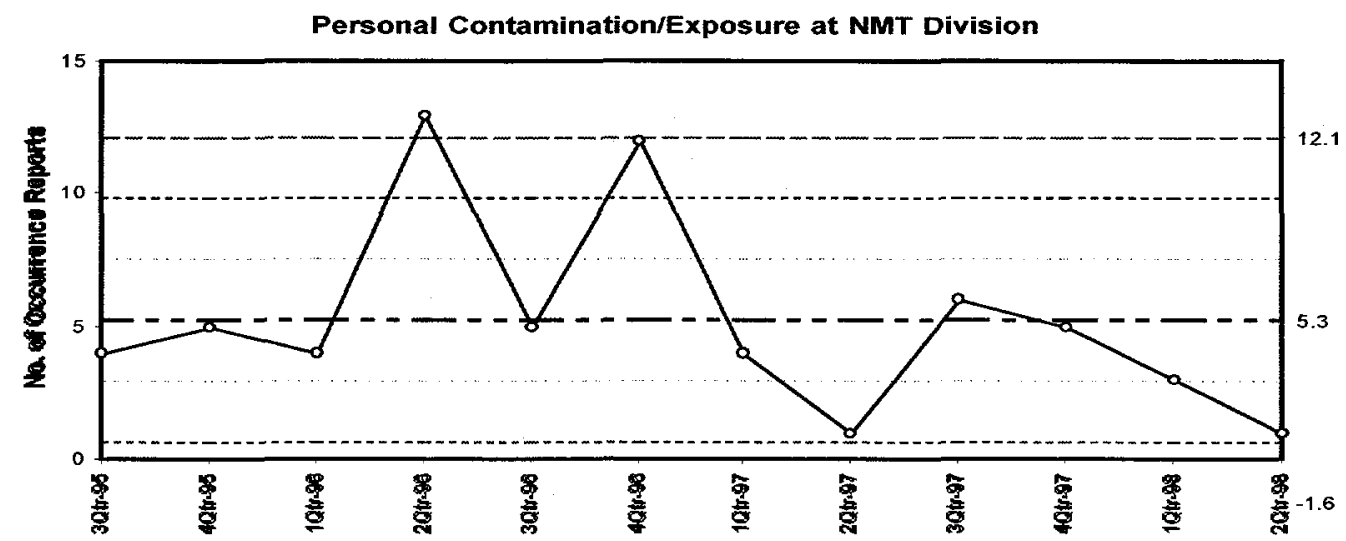

Figure G. Sample Control Chart in Data Package 
The second part of the data packages, the qualitative information, consisted of summaries of each occurrence. The reason for using summaries was related to the number and length of occurrence reports. For example, the Nuclear Materials and Technology Division, which handles and processes radioactive materials, might have 20 occurrences per quarter. Each associated report might range from 6 to 15 pages. A quarterly review of one-paragraph summaries, therefore, seemed more fitting and practicable than a time-consuming review of 20 full-length reports. Besides, the summaries were only intended to be jumping-off points for discussion and analysis; if a complete report had to be referenced, that could easily be done. Figure $\mathrm{H}$ shows a typical summary for the data package. Note the summary contains a brief synopsis of causal factors and corrective actions.

\section{Radioactive Contamination Detected on Skin}

ALO-LA-LANL-CMR-1996-0010

On March 4, 1996, a radiological control technician (RCT) detected alpha contamination on the skin of two Johnson Controls, Inc (JCI) employees at the Chemistry and Metallurgy Research (CMR) facility. The employees had removed filters in the plenum for exhaust fan FE-32. As specified in the radiological work permit (RWP) and prejob briefings, the employees had each worn personal protective equipment (PPE) that included a Tyvek suit, two pairs of cloth coveralls, and a supplied air mask. After removing and disposing of the old filters, the workers doffed their protective equipment with the assistance of an RCT. The RCT detected alpha contamination on the skin and inner coveralls of both employees. The root cause of this occurrence was Equipment Material Problem, Defective of Failed Material. The combination of multiple layers of protective clothing and rigorous work caused the two employees to perspire heavily. The perspiration leached contamination through multiple layers of protective clothing. In addition, both employees' Tyvek clothing became damaged during the work. Although the employees taped over damaged areas (as instructed by the RCT's), contamination migrated through these areas and adhered to damp surfaces in the coveralls. A contributing cause for this occurrence was Personnel Error, Other Human Error. One employee's cheek and neck became contaminated during the removal of the supplied air mask.

Corrective Actions: (1) replace Tyvak suits with a sturdier, more breathable, and more water-resistant suit for filter removal work or other rigorous work that may involve damaged PPE, heat stress, worker perspiration, or external moisture.

Figure H. Sample Occurrence Summary in Data Package

\section{Analysis Section}

Planners consulted with division managers on the approach to analysis. They evolved a selfassessment strategy in which line managers would review the charts and summaries and use groups of line managers and subject-matter experts to spot problem areas in the data. Managers were asked to document their analysis, identify lessons learned, and assign corrective actions. The following guidance was provided for meeting the measure requirements: 


\section{Meets Expectations}

- The Laboratory develops a written annual summary of the selected ES\&Hsignificant occurrences for the review period, and a management assessment is performed with appropriate corrective actions and target completion dates identified.

- All identified actions are tracked to closure, and auditable records are maintained.

\section{Exceeds Expectations}

- A proactive system is in place to provide management review of selected occurrences on a quarterly basis and to ensure immediate action if there is evidence of significant adverse trends.

For a number of reasons, then, this was not a traditional performance measure. In the first place, there were no numerical targets. This was related to the idea that "paying attention to the accident cycle" is a regressive method of analysis. Instead of focusing purely on numbers of accidents, line managers were encouraged to perform a qualitative analysis of the division's occurrences. In fact, the performance measure simply required that managers pay attention to the occurrences on a quarterly basis, write an analysis, and correct significant problems. Documenting the process fulfilled the requirement of the measure.

In sum, the structure of the data package and analysis was for senior line management to respond to a tailored report describing the occurrences within the division and to identify and implement systemic types of corrective actions.

\section{Modifications to the Original Program}

The original review structure for the program was soon modified. Line management identified inconsistencies in the data packages and asked for modifications. The first modification addressed occurrence ownership. According to DOE convention, occurrence reports identify a single facility as "owner" of the occurrence. Usually the owner is the management of the facility where the occurrence took place. It became evident, however, that this geographical method of assigning occurrence ownership did not account for the frequent secondary involvement of visitors, support personnel, or tenants from outside of the facilityowning organization.

For example, if an ESH Division radiological control technician-a support employee-violated a procedure and caused an accident at a host facility, then ESH Division should also be identified as part owner of that occurrence. To identify these "multiple ownership occurrences," ESH-7 began identifying organizations that partly owned or had a stake in the corrective actions. Those organizations were also sent data packages for analytical review. 
Another modification to the review structure was developed. Line managers/analysts pointed out that some data was "old." The data packages only included summaries of occurrences for which investigations had been completed and causal factors and corrective actions had been assigned. This investigative process took from a few weeks up to a year or more to complete. As a result, some managers felt they were looking at parchments describing old organizational structures, absent personnel, or outdated corrective actions. To remedy this problem, ESH-7 began providing information on incomplete investigations in the data packages.

A third modification involved the development of "horizontal analysis." In the horizontal analysis, LANL subject-matter experts, each responsible for a particular functional area (e.g., radiological protection, packaging and transportation, fire protection), used the line management, or "vertical," analysis as a starting point to analyze the particular safety function for the entire Laboratory. The combined result was to be a thorough examination of LANL occurrences from both organizational and functional perspectives. These analyses were written up in quarterly safety function self-assessments, similar to the division selfassessments, and were intended to stand ultimately as LANL's best evaluation of its institutional safety management systems.

\section{Analysis of Institutional Response}

In 1998, ESH-7 reviewed the management self-assessments. Figure I shows the use of occurrence analysis in the self-assessments for two fiscal quarters in 1998. Of the 16 involved divisions, approximately 9 analyzed occurrences, and fewer actually developed lessons learned or systemic corrective actions. Although the developers had originally viewed occurrence reports as underlying the self-assessment process, line managers often did not refer to them in their write-ups.

\begin{tabular}{lll}
\hline & $98-1$ & $98-2$ \\
\hline Participating Divisions & 16 & 16 \\
Performs Analysis & 9 & 8 \\
Develops Lessons Learned & 7 & 6 \\
Develops Corrective Actions & 6 & 5 \\
\hline
\end{tabular}

Figure I. Occurrence Analysis in Self-Assessments

The review also identified problems in the quality of division occurrence analysis. Many of the occurrence analyses were disjointed and failed to provide significant contextual information. For example, the self-assessments that analyzed occurrences did so in highly specific categories (i.e., authorization basis, radiological protection) but did not discuss overall occurrence patterns or context. Unlike the localized, facility models of analysis at CMR, TA-18, and LANSCE, which required overarching reviews and systemic analysis of all occurrences at the facility, these analyses were disconnected and did not have a coherent viewpoint. In general, the self-assessments did not reflect common cause occurrence analysis and systemic corrective action development. 
This disjointed quality is particularly troublesome for trending and analysis. A single occurrence report may identify multiple points of failure: a faulty procedure, operator error, a failed piece of equipment. To make sense of an occurrence requires soliciting information from a pool of workers, managers, and subject-matter experts. This is truer still for understanding groups of occurrences. The type of systemic, collective analysis of occurrences shown by the facilities in their standdown and restart processes represents the required level of effort. The management self-assessments of occurrences were not of that quality.

Further evidence of this disjointed analysis was the lack of linkage between a division's occurrences and other data resources. For example, the self-assessments did not attempt to link occurrence data with Integrated Safety Management (ISM), the program for managing workplace safety at the Laboratory. Many ISM data resources provide information that is often a precursor or leading indicator of occurrence reports. For example, the Management Walkaround (MWA) system records managers' firsthand observations of facility deficiencies or noteworthy practices. These detailed observations often identify precursors of occurrences. But, because they were not required to do so, the management self-assessments did not provide linkages between these MWA observations and occurrence reports. Nor were other ISM resources such as Safety Concern Program (SCP) data linked to the occurrence analyses.

In sum, the occurrence analyses in the management self-assessments were cursory and not of high quality. The following sections identify causal factors for this poor result in implementing an institutional program of trending and analysis.

\section{Lack of Planning to Implement an Institutional Program}

The first causal factor was a lack of planning in implementing an institutional program. Program developers paid more attention to developing information structures (i.e., charts, summaries, graphs) than to the actual mechanics of implementing the program. The emphasis in the planning process was more on upstream than on critical downstream factors.

Planners failed to fully address critical implementation issues: Was a mentoring or training program necessary for the quarterly occurrence reviews? Should occurrence investigators facilitate the reviews? Would senior line managers actually write the analyses? Who would actually attend the quarterly reviews from each division? Because these details were not addressed or resolved in the planning process, divisions received no clear guidance on actually implementing the quarterly reviews.

Instead, divisions received minimal guidance in the form of memos, occasional meetings, and generic measure requirements. They did not receive sustained, detailed guidance in the analytical process, facilitation of quarterly reviews, or mentoring or formal procedures on analytical processes. In sum, planners did not provide sufficient thought and planning to the implementation of an institution-wide trending and analysis program. 


\section{Lack of Authority and Resources to Implement an Institutional Program}

The second causal factor, a lack of authority and resources to implement an institutional program, is best understood by comparing the successful, localized model of facility occurrence analysis with the less successful institution-wide model. With the facility model, the division directors at CMR, TA-18, and LANSCE stood down operations and initiated restarts that included collective occurrence analysis and systemic corrective action development. In each case, the division director had the requisite authority and resources to ensure implementation of the restart and could mandate the participation of managers, subject-matter experts, and other personnel.

ESH-7, a group within the Environment, Safety, and Health Division (ESH), was assigned the responsibility of developing an institution-wide program of occurrence trending and analysis. However, neither DOE nor LANL invested ESH-7 or any other Laboratory entity with the authority to mandate and enforce such a program. Nor did LANL assign personnel and resources to develop training packages, train divisions in occurrence analysis, mentor and facilitate quarterly occurrence analyses, and ensure the quality of analyses was high.

The combined result of the causal factors, inadequate planning and a lack of authority and resources, resulted in the following impacts at the Laboratory:

- Key division managers were often not involved in the process

- Divisions did not properly conduct periodic, sustained occurrence analysis

- Occurrence analyses often had a disjointed quality

- Divisions did not develop systemic corrective actions

- Facility standdowns became the default mode of responding to clusters of occurrences

\section{Conclusions and Recommendations}

This paper has described a three-stage evolution of LANL response to occurrences: (1) a failure to identify low-consequence incidents that led to reactive management of severe accidents, (2) facility standdowns and restart processes that have included systemic causal analysis of low-consequence incidents, and (3) the development of an institution-wide program of proactive trending and analysis. What can we learn from this evolution?

The CMR, TA-18, and LANSCE standdown and restart processes indicate that Laboratory management has begun to implement mechanisms for using occurrence data in making management decisions. A pattern of valuing a common cause analysis as a way of identifying larger systemic issues is emerging at LANL. As this transition takes place, facilities have begun to use this type of analysis earlier in the facility's standdown so that corrective actions can be better designed to address the systemic issues. But the request for common cause analysis has come only after a standdown. 
This approach is costly and unfortunate. Facility standdowns usually take several months to complete, require enormous effort by the entire facility workforce, place inordinate stress and burden on workers and managers, and result in the loss of time and resources that could have been devoted to programmatic research and development activities.

An obvious lesson can be drawn from the facility experiences: perform a proactive, common cause analysis of less serious incidents and then develop and implement systemic corrective actions before a serious accident occurs or a facility standdown becomes necessary. Most of the goals achieved through the investigation of a serious injury or accident or through the facility restart process can be attained without first having an injury or death or a facility standdown. In addition, the goals can be achieved in less time, with far fewer resources, with less workforce stress and burden, and at less cost.

But to achieve those goals, LANL must devote sufficient attention to the mechanics of actually implementing such an institution-wide program. To ensure the success of such a program, LANL management must commit to provide resources, authorities, and infrastructure for the following:

1. Implement a formal, proceduralized process to continually analyze and correct the causes of individual incidents and near misses. Investigations of these incidents must be performed in sufficient depth to identify underlying causal factors and not simply focus on identifying and correcting direct causes (e.g., personnel errors). Corrective actions should be implemented to mitigate all identified causes, particularly root causes.

2. Implement a formal, proceduralized process to periodically analyze and correct the causes of groups of high- and low-consequence incidents and near misses. A common cause analysis should be performed by groups of managers, workers, and safety professionals trained in this technique. Occurrence investigators (or others trained in the analytical techniques) should be available to facilitate the periodic occurrence analyses. Additional data available for the analyses should include management walkarounds, injury logs, safety concerns or suggestions, workplace audits and assessments, or other locally collected data that may help to identify precursors to incidents. Corrective actions must be developed and properly implemented to address systemic issues discovered during the common cause analysis.

The types of problems described in implementing the LANL trending and analysis program-inadequate planning, lack of authority and resources-must be avoided if such processes are to become the valuable management tool envisioned and not merely a paperwork exercise. The facilities' experiences can illustrate how to reform institutional programs. The hard-won facility lessons can be the starting point for implementing effective institution-wide programs. 